\title{
Currículo contextualizado e permanência do jovem no campo
}

\author{
The contextualized curriculum and young people remaining in the countryside \\ Currículum contextualizado y permanencia del joven en el campo
}

Recebido: 10/03/2021 | Revisado: 16/03/2021 | Aceito: 21/03/2021 | Publicado: 29/03/2021

\author{
Adelcio Menezes de Sousa \\ ORCID: https://orcid.org/0000-0003-4578-290X \\ Universidade Federal do Recôncavo da Bahia, Brasil \\ E-mail: sousamadelcio@gmail.com \\ Naiara Serafim Santos Mota \\ ORCID: https://orcid.org/0000-0001-7860-6705 \\ Universidade do Estado da Bahia, Brasil \\ E-mail: naiaramota_nw@hotmail.com \\ Rosineide Pereira Mubarack Garcia \\ ORCID: https://orcid.org/0000-0002-9901-2495 \\ Universidade Federal do Recôncavo da Bahia, Brasil \\ E-mail: rose.mubarack@gmail.com
}

\begin{abstract}
Resumo
Aborda-se no presente artigo, as discussões proferidas no I Congresso Internacional e III Congresso Nacional Movimentos Sociais e Educação, realizado pelo grupo de estudos Movimentos Sociais, Diversidade e Educação do Centro de Estudos e Pesquisas em Educação e Ciências Humanas da Universidade Estadual de Santa Cruz (UESC), no sentido de apresentar a proposta de Educação no Campo adotada pela Casa Familiar Rural de Presidente Tancredo Neves, localizada na Região do Baixo Sul da Bahia, também conhecida como "Pedagogia da Alternância", vislumbrando refletir a contribuição desta instituição na valorização do meio rural para o desenvolvimento socioeconômico cultural e educacional dos jovens, suas famílias e comunidade. Na construção dessa reflexão, apoiamo-nos na pesquisa bibliográfica que nos possibilitou um apanhado geral sobre os principais trabalhos realizados, capazes de fornecer dados atuais e relevantes relacionados ao tema da pedagogia da alternância e a contextualização do currículo. A pedagogia adotada pela CFR-PTN, que não dissocia a prática da teoria, traz a autonomia do educando como ponto central ao desenvolvimento da aprendizagem, deixando evidente que o currículo quando pensado em prol dos educandos, torna a aprendizagem mais significativa e prazerosa.
\end{abstract}

Palavras-chave: Contextualização; Pedagogia da alternância; Autonomia; Juventude.

\begin{abstract}
In this article, we address the discussions held at the I International Congress and III National Congress of Social and Education Movements, organized by the Social Movements, Diversity and Education Study Group at the Center of Studies and Research in Education and Human Science at the State University of Santa Cruz (UESC). We present the proposal of Education in the Countryside adopted by the Presidente Tancredo Neves Rural Family House (CFR-PTN), located in the Southern Lowlands region of Bahia, also known as "rotation education". We reflect on this institution's contribution towards valuing the rural environment for the socio-economic, cultural and educational development of young people, their families and communities. In order to construct this reflection, we utilized bibliographic research, which enabled us to gain a general overview of the main work which has been conducted until this time. This provided current and relevant data on the topic of rotation education and the contextualized curriculum. The pedagogy adopted by CFR-PTN, which does not separate practice from theory, favors student autonomy as a central point to enhance their education, clearly showing that when the curriculum is designed for the students, learning becomes more meaningful and enjoyable.
\end{abstract}

Keywords: Contextualization; Rotation education; Autonomy; Young people.

\section{Resumen}

Se aborda en el presente artículo, las discusiones realizadas en el 1er. Congreso Internacional y 3er. Congreso Nacional de Movimientos Sociales y Educación, realizado por el grupo de estudios de Movimientos Sociales, Diversidad y Educación del Centro de Estudios e Investigaciones en Educación y Ciencias Humanas de la Universidad Estatal de Santa Cruz (UESC) con el objetivo de presentar la propuesta de Educación en el Campo adoptada por la Casa Familiar Rural de Presidente Tancredo Neves, localizada en la Región del Bajo Sur de Bahía, también conocida como "Pedagogía de Alternancia", buscando reflejar la contribución realizada por esta institución en la valorización del medio rural para el desarrollo socioeconómico, cultural y de educación de los jóvenes, sus familias y la comunidad. En la construcción de esta reflexión, nos apoyamos en la investigación bibliográfica que nos 
facilitó una revisión general sobre los principales trabajos realizados, capaces de proveer datos actuales y relevantes relacionados al tema de la pedagogía de alternancias y la contextualización del currículum. La pedagogía adoptada por la CFR-PTN, que no disocia la práctica de la teoría, desarrolla la autonomía del estudiante como punto central del desarrollo del aprendizaje, quedando en evidencia que cuando el currículum se piensa con foco en los alumnos, el mismo se vuelve más significativo y agradable.

Palabras clave: Contextualización; Pedagogía de alternancia; Autonomía; Juventud.

\section{Introdução}

Sabe-se que há muito tempo o currículo escolar ressalta o modelo cultural de uma classe social dominante em detrimento de outras, expondo então, o caráter excludente desse sistema educacional que visa valorizar um currículo monocultural e eurocêntrico privilegiando a cultura branca, masculina e cristã e desprezando as demais culturas as quais foram relegadas a inferioridade inclusive no aspecto social. Diante disso, surge o desejo por uma educação que valorize o contexto social dos educandos, suas experiências, seus anseios e perspectivas, emergindo um currículo para a emancipação e libertação, que garanta aos educandos aprender com sua realidade, tendo uma escola ativa e democrática.

Neste âmbito, o presente artigo visa apresentar a proposta de Educação no Campo adotada pela Casa Familiar Rural de Presidente Tancredo Neves, na Região do Baixo Sul da Bahia, também conhecida como "Pedagogia da Alternância", vislumbrando refletir a contribuição desta instituição na valorização do meio rural para o desenvolvimento socioeconômico cultural e educacional dos jovens, suas famílias e comunidade. Na construção dessa reflexão, apoiamo-nos na pesquisa bibliográfica que nos possibilitou um apanhado geral sobre os principais trabalhos realizados, capazes de fornecer dados atuais e relevantes relacionados ao tema da pedagogia da alternância e a contextualização do currículo.

A proposta Educacional da Casa Familiar Rural de Presidente Tancredo Neves (CFR-PTN), assim nos reportaremos à instituição ao longo do artigo, vem ao encontro da proposta de Políticas Públicas para a Educação Profissional e Tecnológica que busca integrar à Educação Básica ao mundo do trabalho para a geração de renda, pois treina, capacita e estimula o jovem e, ao mesmo tempo, o mantém em contínuo crescimento e o incentiva, por meio da convivência com as famílias, ao empresariamento. Sendo assim, se faz necessário refletirmos sobre este modelo inovador de educação desenvolvido há alguns anos na cidade de Presidente Tancredo Neves - Bahia, o qual vem apresentando resultados cada vez mais satisfatórios, transformando vidas e valorizando o Campo enquanto espaço para viver dignamente, com qualidade e sustentabilidade.

No primeiro momento, é apresentado um breve histórico da Casa Familiar Rural de Presidente Tancredo Neves, em seguida Aspectos Conceituais e Históricos da Pedagogia da Alternância são abordados de forma sucinta e objetiva, no momento seguinte a contextualização do currículo enquanto meio favorecedor de uma educação mais significativa ganha espaço em nossas reflexões possibilitando-nos apresentar os aspectos metodológicos agregados ao currículo da CFR-PTN favorecendo então um leque de possibilidades para nossas considerações finais que, sem dúvidas nos concede outras tantas reflexões acerca da educação que desejamos para nossa juventude.

\section{Metodologia}

A pesquisa pressupõe descrever as características de uma população, um fenômeno ou experiência para o estudo realizado. A pesquisa descritiva exige do investigador uma série de informações sobre o que deseja pesquisar. Esse tipo de estudo pretende descrever os fatos e fenômenos de determinada realidade (Triviños, 1987).

Nessa mesma linha, Koche (2011, p. 124) afirma que "na pesquisa descritiva não há a manipulação a priori das variáveis. É feita a constatação de sua manifestação a posteriori". Ancorando-se no itinerário pavimentado por Gil (2007, p. 17), quando define a pesquisa como o "procedimento racional e sistemático que tem como objetivo proporcionar respostas", este texto recorreu ao método que compreende o estudo com caráter descritivo utilizando a observação e o registro dos fatos, 
visando a geração de conhecimentos para aplicação prática, dirigidos à solução de problemas específicos (Gerhardt \& Silveira, 2009).

Procedimentalmente, tencionando correlacionar as observações realizadas, recorreu-se à pesquisa documental, catalisadora de fontes mais diversificadas e dispersas, sem tratamento analítico, a exemplo de relatórios e documentos oficiais e/ou institucionais (Fonseca, 2002).

\section{A Casa Familiar Rural de Presidente Tancredo Neves: breve histórico}

A Casa Familiar Rural de Presidente Tancredo Neves (CFR-PTN) é uma Instituição de Educação Profissional, formada por uma Associação de Pais e produtores rurais, regida por seu Estatuto Social e Regimento Escolar e está situada na Fazenda Novo Horizonte, BR 101, Km 315, no município de Presidente Tancredo Neves - Bahia.

Fundada em agosto de 2002, a execução de seus projetos iniciou-se em junho de 2003, a partir do convênio firmado entre a Prefeitura Municipal de Presidente Tancredo Neves e o Ministério da Agricultura, Pecuária e Abastecimento. Desde então, a CFR-PTN, vem tendo os apoios de parceiros sociais ligados ao poder público e privado que oferecem incentivos importantes para a consecução de suas atividades.

Em maio de 2009, através do parecer n 104/2009, o Conselho Estadual de Educação (CEE), reconheceu formalmente o Curso de Educação Profissional Técnica em Agropecuária, ministrado pela CFR-PTN, como integrante da grade curricular do nível médio, tornando a primeira Casa Familiar Rural a certificar com Ensino Médio integrado ao Técnico no Estado da Bahia. Desde a sua implantação, o projeto vem apresentando resultados que apontam para a sua continuidade com perspectivas de ampliação das ações empreendidas, considerando a mobilização das comunidades rurais envolvidas e das parcerias existentes.

A Unidade Escolar para formação de adolescentes e jovens Técnicos em Agropecuária está sediada na Fazenda Novo Horizonte, uma propriedade com 128 hectares, onde estão instaladas Unidades Demonstrativas, além do Campo Demonstrativo de Tecnologia da Mandioca e Fruticultura (CDTMF), em parceria com a Empresa Brasileira de Pesquisas Agropecuárias (EMBRAPA) e o Centro Vocacional Tecnológico Territorial (CVTT), todas essas estruturas servem de aula prática e estágio para os estudantes.

A experiência da Instituição já contempla a formação de nove turmas, num total de 267 jovens beneficiados e outros 105 estão em formação, por meio de um sistema de aprendizado de alternância, em cursos de duração de três anos e ensino de nível médio profissionalizante.

A CFR-PTN em parceria com a Cooperativa dos Produtores Rurais de Presidente Tancredo Neves (COOPATAN), tem exercido um papel fundamental no desenvolvimento rural regional, sendo organizações líderes no fomento das cadeias produtivas regionais, no combate ao êxodo rural e na geração de renda através da inserção de adolescentes no processo educacional e produtivo.

A missão da CFR-PTN consiste em promover a Educação Profissional de qualidade aos adolescentes em estado acentuado de exclusão e vulnerabilidade social, estimulando a permanência no campo e na Agricultura Familiar. Em sinergia permanente com a COOPATAN potencializando e consolidando os recursos e resultados dos princípios do associativismo e cooperativismo, tem como objetivo a formação de adolescentes comprometidos com o desenvolvimento de suas comunidades e da região.

Assim, diante do exposto, a Casa Familiar Rural entende que o adolescente que passou pelo processo formativo através do Curso de Educação Profissional Técnica em Agropecuária integrada ao Ensino Médio sendo acompanhado até sua inserção numa cooperativa assegurará o desenvolvimento do jovem, reduzindo significativamente a exposição às maiores mazelas que atinge o jovem na atualidade, sobretudo, os adolescentes rurais como violência, drogas, prostituição, 
criminalidade, fome, gravidez na adolescência, entre outros (Estatuto - $7^{\mathrm{a}}$ Versão, 2014).

\section{Aspectos Conceituais e Históricos da Pedagogia da Alternância}

A pedagogia da alternância surgiu na França, em 1935, como Casa Familiar Rural no povoado de Lot et Garonne. A iniciativa partiu de um grupo de pais agricultores que buscavam solucionar dois grandes problemas. De um lado, as questões relacionadas ao ensino regular que, por ser direcionado para as atividades urbanas, levava os adolescentes campesinos a abandonar a terra. E de outro lado, a necessidade de fazer chegar ao campo a evolução tecnológica de que precisavam. Criaram então a primeira "Casa Familiar Rural", lá chamada de Maison Familiale Rurale, onde os jovens passavam duas semanas recebendo conhecimentos gerais e técnicos voltados para a realidade agrícola regional e duas semanas nas propriedades rurais, aplicando os conhecimentos recebidos, tal prática foi chamada de "Pedagogia da Alternância" (Gimonet, 2007).

Foi na década de 1960 que a Pedagogia da Alternância veio para o Brasil, trazida da Itália sob influência das Escolas Famílias Agrícola (EFAS). O primeiro estado brasileiro a implantar a experiência foi o Espírito Santo - ES, sobre a intermediação da Igreja Católica assim como na França (Oliveira, 2013).

Um marco histórico na pedagogia da alternância no Brasil ocorreu em 1968 com a fundação do MEPES - Movimento de Educação Promocional do Espírito Santo (MEPES) que é uma entidade civil mantenedora das EFAs, que se caracteriza como uma organização filantrópica e sem fins lucrativos de inspiração Cristã (Andrade \& Andrade, 2012).

O movimento da Pedagogia da Alternância no Brasil está dividido em dois momentos distintos: de um lado, o movimento das (EFAs) Escolas Famílias Agrícolas, influenciado pelas experiências italianas, de outro lado o movimento que reúne as (CFR) Casas Familiares Rurais (Estevam, 2003). Embora as Escolas Famílias Agrícolas (EFAs), desenvolvam suas metodologias a partir da Pedagogia da Alternância, há uma diferença quanto a organização do tempo/escola e tempo/família dos jovens em relação às Casas Familiares Rurais (CFRs). Na primeira os alunos ficam quinze dias na escola e quinze dias na propriedade, com a família. Já na segunda o educando permanece uma semana na escola e duas semanas com a família.

As EFAs se caracterizam por apresentarem: $1^{\circ}$ ) uma metodologia pautada no princípio da alternância que integra o meio socioprofissional (família/comunidade) e o centro escolar; $2^{\circ}$ ) uma associação responsável nos diversos aspectos: econômicos, jurídicos, de gestão etc.; $3^{\circ}$ ) a educação e a formação integral da pessoa e finalmente, $4^{\circ}$ ) o desenvolvimento do meio local através da formação de seus próprios atores. Essas características são consideradas condições sine qua non das EFAs (Andrade \& Andrade, 2012).

O processo de implantação das Casas Familiares Rurais (CFRs) no Brasil se deu por outro viés histórico. No final da década de 1970, uma equipe governamental do Ministério da Educação ficou conhecendo a experiência numa viagem realizada à França. Após conhecerem o funcionamento das Casas Familiares Rurais iniciaram as discussões para a implantação de uma Casa Familiar Rural no Brasil (Oliveira, 2013).

A primeira região a receber uma Casa Familiar Rural foi o Nordeste, no estado de Alagoas, mais precisamente, o município de Arapiraca, na década de 1980. Mas por conta de uma série de problemas políticos daquele município, a Casa Familiar Rural foi fechada. Contudo, outras regiões brasileiras também se interessaram pela proposta de ensino por alternância.

Para responder jurídica e legalmente por estas instituições de ensino, foram fundadas as Associações Regionais das Casas Familiares de cada região. No Sul do Brasil existe a Associação Regional das Casas Familiares do Sul ARCAFAR/SUL, (Oliveira, 2013).

A pedagogia da alternância é uma metodologia de organização do ensino escolar que agrega diferentes experiências formativas difundidas ao longo de tempos e ambientes distintos, seu intuito é uma formação profissional (Teixeira et al., 2008). Trata-se de uma proposta pedagógica, ainda pouco difundida no Brasil. Ela foi criada em decorrência da observação de alguns agricultores franceses, perante a rejeição e desmotivação de seus filhos, em face da pedagogia desenvolvida nas escolas 
urbanas que frequentavam (Queiroz et al., 2006).

\section{Currículo e Contextualização: um Diálogo Necessário}

Sabe-se que o currículo é uma seleção de conteúdos culturais que vão fazer parte do projeto educativo proposto pela escola, sendo também um processo pelo qual a escola se organiza, propõe os seus caminhos e a orientação para a prática, ou seja, sobre o que, quando e como ensinar e sobre o que, quando e como avaliar. Contudo, o currículo em suas mais amplas conceituações ultrapassa a simples seleção de conteúdo.

A prática a qual se refere o currículo é definida através de posições didáticas, políticas, administrativas e econômicas, de uma determinada realidade social, que segundo Sacristán (2000), escondem-se muitos pressupostos, teorias parciais, esquemas de racionalidade, crenças, valores etc., que visam o condicionamento da teorização sobre o currículo. Visto isto, é importante ressaltar que o currículo em sua essência é uma "construção cultural", como afirma Grundy (1987, p. 5), pois se trata de organização de práticas diversas que envolvem a educação e seu processo.

O currículo reflete o indivíduo que queremos formar, a sociedade que desejamos ter, e expõe a cultura que pretendemos privilegiar. Assim, valorizar o contexto sociocultural dos sujeitos é o ponto que direciona toda a prática educacional, as pessoas se constroem e constroem seu conhecimento a partir do seu contexto, considerando a bagagem histórica que já traz, tornando a aprendizagem bem mais significativa. A partir do currículo, questionamos o tipo de homem que queremos formar e, consequentemente, qual sociedade almejamos construir. Neste diálogo, a didática vem apoiando o processo de construção social, dando ênfase a questões sobre como ensinar, para quem ensinar, o que ensinar e o porquê ensinar.

A partir destas reflexões, ressaltamos a importância de um currículo contextualizado e de uma didática que não dissocie a prática da teoria, em prol de um sistema educacional que realmente apresente resultados satisfatórios no que tange o processo de ensino e aprendizagem dos envolvidos. Candau enfatiza o seguinte:

O professor tem que se adaptar ao meio e tentar transmitir sua didática, partindo de um princípio onde o meio em que o aluno vive deve ser levado em conta, assim buscando sua cultura e sua realidade. Daí então o professor começa a apresentar para o aluno o mundo que ele não conhece (Candau, 1999, p. 52).

Trazer o contexto social dos indivíduos, suas experiências, interesses e habilidades para o âmbito escolar favorece seu desenvolvimento integral e desperta a criticidade para as questões de interesse social que surge em sua comunidade. Tais aspectos são significativos quando se observa a constatação de Lima (2020, p. 6) "historicamente as escolas do campo foram pensadas a partir do modelo de educação implementado na cidade, desconsiderando as especificidades sociais, culturais, econômicas, políticas e ambientais do mundo rural".

Adotando o currículo contextualizado, a Casa Familiar Rural vem mudando a vida de jovens, famílias e comunidades na cidade de Presidente Tancredo Neves-Bahia. A CFR-PTN oferece aos seus alunos um laboratório de desafios conectado ao mundo real, onde os jovens aprendem a serem empreendedores sendo empreendedores. A intenção é "Aprender Fazendo". Sabe-se que os currículos escolares desarticulados da realidade local funcionaram sempre como um passaporte para os grandes centros urbanos do país, por isso a CFR-PTN adota um currículo contextualizado que traz em sua essência a valorização do Campo, da zona rural, enquanto espaço possível de se viver com qualidade e tranquilidade.

Adotando a Pedagogia da Alternância como metodologia-base, a CFR-PTN oferece o Ensino Médio Integrado ao Curso Técnico em Agropecuária. Sua Missão é Promover Educação Profissional de Qualidade a Jovens Agricultores, estimulando-os a permanência no Campo e na agricultura familiar de maneira digna, tendo como princípio o desenvolvimento social pautado na sustentabilidade socioeconômica e ecológica. O adolescente permanece uma semana em regime de internato 
na Casa Familiar, recebendo aulas específicas da Base Técnica assim como da Base Nacional Comum, e duas semanas na unidade-família replicando os conhecimentos aprendidos. A Casa forma Jovens residentes na zona rural, filhos de produtores, para serem Empresários em suas propriedades e atuarem como Líderes em suas comunidades, ou seja, como Agentes de Desenvolvimento Local oportunizando ao Jovem, a vivência da ação-reflexão-ação na educação pelo trabalho e com a troca de experiências dos saberes compartilhados com suas famílias e comunidades, sendo agente do seu próprio destino.

$\mathrm{Na}$ formação, os adolescentes são instruídos com conhecimentos técnicos e específicos das diferentes culturas e criações, associativismo/cooperativismo e administração rural. Como resultado, eles desenvolvem aptidões para elaborar e implantar projetos de negócios agropecuários em suas propriedades, garantindo assim, geração de renda para a unidadefamília, consolidando o processo educativo associado à qualificação profissional para o trabalho. Nesse âmbito, compreendemos que, segundo Forquin (1993, p. 144), "é necessário que o que se ensina valha a pena".

Ser agente de seu próprio destino caracteriza a pedagogia adotada pela CFR-PTN, com um currículo bastante flexível e uma didática diferenciada, os Jovens empresários são impulsionados a lidar com a própria autonomia, onde constroem o conhecimento nas vivências com os colegas, nos diálogos e na execução de seus projetos. São desafiados a criarem e irem em busca de bons resultados, almejando sempre a qualidade de vida no campo com sustentabilidade. Surpreender as pessoas é o combustível para esses jovens empreendedores.

A proposta pedagógica em questão tem em sua essência o processo de construção e reconstrução, em que o jovem, na relação teoria e prática, tem o contato com a sua realidade, partindo das experiências que vive, conhece e domina para a descoberta do novo, do saber do outro. A construção do saber grupal a partir do saber individual, o desenvolvimento da criatividade sempre observando o potencial de cada um. Na CFR-PTN;

Por meio da pesquisa sobre a realidade, o educando OBSERVA seu meio de inserção. Por meio da análise da realidade, comparações, generalizações e sínteses REFLETE a realidade no meio escolar. Com o surgimento de novas interrogações e pesquisas EXPERIMENTA E TRANSFORMA seu meio de inserção (UNEFAB, 2000).

A inovação educacional é necessária, porém só trará resultados positivos se pensada tendo como base o contexto social do meio no qual a instituição esteja inserida. A educação precisa fazer sentido na realidade das pessoas no lugar onde estão. Contextualizar o currículo e consequentemente a forma de ensinar, requer uma ruptura da concepção tradicional e colonizadora da educação. Para Martins (2001, p. 31);

Contextualizar, portanto, é esta operação mais complicada de descolonização. Será sempre tecer o movimento de uma rede que concentre o esforço em soerguer as questões "locais" e outras tantas questões silenciadas na narrativa oficial, ao status de "questões pertinentes" não por serem elas "locais" ou "marginais', mas por serem elas "pertinentes" e por representarem a devolução da "voz' aos que a tiveram usurpada, roubada, negada historicamente.

Neste sentido, currículo e contextualização devem andar juntos, e nesta caminhada a sociedade será beneficiada, sua cultura será valorizada e os sujeitos em questão aprenderão mais sobre sua realidade, podendo agir sobre ela para realizar as mudanças necessárias. O currículo contextualizado leva em consideração o conhecimento armazenado durante a vida dos indivíduos, possibilitando assim uma aprendizagem mais significativa. No que tange a aprendizagem significativa, a CFR-PTN também foca no uso das Tecnologias da Informação e da Comunicação (TICS) instituindo não só novas formas de comunicação entre as pessoas como também novas formas de pensar, de elaborar o conhecimento e articulá-lo à realidade na qual se está inserido. 


\section{Aspectos Metodológicos Agregados ao Currículo}

A CFR-PTN possui características específicas. Ministra um Ensino Rural no intuito de desenvolver a integração dos jovens com as suas unidades-família e a comunidade em regime de internato associado à prática da PEDAGOGIA da ALTERNÂNCIA. Tem capacidade para 03 turmas de no máximo 35 jovens cada uma, em cada alternância. Isto significa que, enquanto uma turma permanece na CFR-PTN, duas turmas estão nas propriedades e recebem a visita dos Monitores que os orientam no Plano de Estudos para desenvolvimento dos projetos educativos-produtivos.

A Assessoria Pedagógica contribui com a formação dos Monitores durante o planejamento, a execução e avaliação dos jovens. Os Monitores são responsáveis para desenvolver as atividades na CFR-PTN e nas propriedades dos jovens e Unidade-família. Nesse processo, a equipe oferece tempo, presença, conhecimento, experiência e exemplo aos jovens e famílias nas comunidades.

O pressuposto metodológico que sedimenta a educação destes jovens tem sustentação na intencionalidade do afeto como ponto de partida e da cidadania como ponto de chegada. O trabalho permeia todo o processo formativo associando a teoria à prática. Compreendemos que o desenvolvimento sustentável passa pelo desenvolvimento das dimensões humana, social, econômica e ambiental.

A Casa Familiar Rural é o resultado da organização da sociedade civil e da soma de esforços dos Governos Federal, Estadual, Municipal e da iniciativa privada, que formataram um autêntico modelo de Governança em prol do desenvolvimento territorial, integrado e sustentável.

A pedagogia da alternância nas Casas Familiares Rurais proporciona uma formação que consiste, mais especificamente, em “Aprender a Aprender”, como também predispõe à formação permanente. Esta formação consiste, particularmente, no desenvolvimento pessoal e social da imaginação e criatividade. Oferece também a capacidade de engajamento, relacionamento, espírito de cooperação, trabalho em grupo, e favorecimento ao progresso. Promovendo, nesse contexto "os anseios de um currículo voltado para as necessidades da população rural” (Sousa \&Garcia, 2020, p. 84416).

A prática da Pedagogia da Alternância, desenvolvida na CFR-PTN, tem promovido o homem/mulher do campo dentro de sua própria cultura e realidade socioeconômica e se concretiza, na medida em que adota os princípios e os instrumentos didáticos-pedagógicos específicos que a caracteriza e a diferencia da escola convencional, são eles:

a) Plano de Formação: programação dos temas (conteúdos) de estudo integrando as disciplinas da Educação Técnica e Educação Básica, temas estes estruturados entre currículo formal e saberes locais;

b) Plano de Estudo: plano com todos os temas estudados num ciclo. Assim, os jovens levam para discutir com a sua família e fazem reflexão sobre o tema da Alternância programada no Plano de Formação;

c) Visita à Unidade-Família: a visita é algo comum na realidade social do campo de atuação da CFR-PTN. Os monitores visitam a família quando o jovem está em sua casa, e a espontaneidade desse momento é fruto de uma troca de ideias sobre questões sócio pedagógicas e técnico-agrícolas ligadas diretamente ao meio familiar e escolar. Nesse sentido, a visita é um dos instrumentos sócio pedagógicos de promoção e não apenas momento de encontro. Ela também é um estímulo para o monitor interagir e ser mais solidário com o meio humano em que se encontra e atua como educador;

d) Visitas e Viagem de Estudo: é realizada em um lugar mais distante e com característica diferente da dos jovens. Esse contato com outra realidade ajuda na aprendizagem e com ela estimula o espírito crítico complementando a visão geral de fenômenos sociais e ambientais e tenta ampliar horizontes, complementar conhecimentos, além de globalizar a visão dos fenômenos e fatos. Geralmente são realizados a centros de pesquisas agropecuárias;

e) Ficha Pedagógica: é a maneira de organizar a comunicação com a família e a CFR-PTN. Esse Caderno retrata as atividades desenvolvidas na escola e na propriedade;

f) Pesquisa Participativa Coletiva (PPC) e Seminários Rurais: têm a finalidade de levar o jovem a conhecer sua 
comunidade através da Pesquisa Participativa, onde é feito um diagnóstico da região (levantamento dos serviços básicos de saúde e educação, saneamento básico e estrutura da comunidade, uso de agrotóxico, utilização de Equipamento Individual EPI e preservação ambiental) e logo depois, socializado através de um seminário, geralmente aos domingos com a participação da população local;

g) Projetos Educativos-Produtivos (PEP): consiste na implantação de um módulo de 1 a 2 ha de uma cultura (mandioca, banana, abacaxi, aipim) com apoio da unidade-família, que assume a mão de obra e da CFR-PTN que apoia com a doação de insumos agrícolas e preparo de áreas. Os PEP's permitem aos adolescentes colocar em prática todo conhecimento adquirido na CFR-PTN, além de possibilitar a geração de renda com a colheita para a família. Tais projetos são considerados cruciais para a transformação social dos jovens e, consequentemente, suas Unidades-família inseridas no processo de formação da CFR-PTN, pois a renda auferida com a venda da produção permite melhorias significativas, sobretudo, no aspecto alimentar, estrutural e em muitos casos a aquisição de terras;

h) Ações Multiplicadoras: A CFR-PTN tem se consolidado como um centro de formação para jovens empresários rurais que levam os conhecimentos adquiridos para suas comunidades, promovendo assim, o desenvolvimento de suas unidades-famílias e agricultores familiares do entorno. A transferência de tecnologia é um compromisso da Instituição com o desenvolvimento sustentável nas comunidades. O jovem quando leva até o local onde vive os conhecimentos e novas tecnologias de produção adquiridos na CFR-PTN e nas viagens de estudos às Instituições de pesquisas como a Empresa Brasileira de Pesquisa Agropecuária (EMBRAPA), replicando através de Ações Multiplicadoras e dias de Campo e implantação dos seus Projetos Educativos-Produtivos, transforma essa área em modelo referência na comunidade.

\section{Considerações Finais}

Diante do exposto, para alcançarmos uma educação de qualidade, se faz necessário que repensemos os modelos curriculares apresentados por nosso sistema educacional até o presente momento. $\mathrm{O}$ agora é o tempo ideal a começarmos essa reconstrução, onde se caracteriza como papel dos professores, diretores, secretários, pais e demais sujeitos envolvidos neste objetivo comum, estarem sempre atentos ao que é apresentado como currículo para a escola, sendo necessário que se faça uma análise se este se adapta a realidade dos educandos e comunidade, indagando sempre qual o ideal de homem que o currículo em questão deseja formar, se ele apresenta abertura para reflexões de temas sociais diversos e se há espaço para a bagagem de conhecimento que os alunos trazem para sala de aula. Estes são alguns dos elementos que quando elaborados pensando-se em uma pedagogia social crítica e reflexiva eleva-se a qualidade educacional da instituição.

O projeto apresentado neste artigo traz a autonomia do educando como ponto central ao desenvolvimento da aprendizagem, deixando evidente que o currículo quando pensado em prol dos educandos, torna a aprendizagem mais significativa. Contextualizar o currículo possibilitando uma didática que não dissocie a prática da teoria leva a escola/instituição a resultados nunca antes imaginados. Isso faz parte da inovação, cada projeto busca atingir um determinado público-alvo, contudo o aluno/educando/sujeito/indivíduo e seu contexto é a base que fomenta todo processo de ensino/aprendizagem.

Essas concepções alicerçam o processo formativo da CFR-PTN. O currículo foi concebido considerando a autonomia do jovem, como sujeito de direito e capaz de pensar o local e os saberes onde vive, interagindo e contribuindo com os diversos atores na consolidação de uma educação contextualizada e pensada de acordo com suas necessidades e experiências.

Por fim, é notório que o processo formativo da Instituição objeto deste artigo constitui-se um ambiente fecundo para futuras investigações, além das pesquisas em curso por pesquisadores de diversas áreas do conhecimento. Nesse sentido, recomenda-se a exploração de categorias teóricas implicadas com a avaliação da aprendizagem, avaliação de impacto do processo formativo, juventude rural, entre outros temas multidisciplinares. 
Research, Society and Development, v. 10, n. 4, e2210413732, 2021

(CC BY 4.0) | ISSN 2525-3409 | DOI: http://dx.doi.org/10.33448/rsd-v10i4.13732

\section{Referências}

Andrade, G. S. \& Andrade, E. S. Historiando a pedagogia da alternância e a escola família agrícola do sertão da Bahia (2012). Entrelaçando: Revista eletrônica de Cultura e Educação, 2 (6), 61-72. https://www2.ufrb.ed u.br/revistaentrelacando/index.php/edicoes-entrelacando/43-educacao-movimento-07.

Candau, V. M. (org.) (1999). A Didática em Questão (17a ed.). Vozes.

Casa Familiar Rural de Presidente Tancredo Neves (2014). Estatuto. (7a Versão).

Estevam, D, O. (2003). Casa Familiar Rural. A formação com base na Pedagogia da Alternância. Insular.

Fonseca, J. J. S. (2002). Metodologia da pesquisa científica. UEC.

Forquin, J.C. (1993). Escola e cultura: as bases sociais e epistemológicas do conhecimento escolar (1a ed.). Porto Alegre: Artes Médicas.

Gerhardt, T. E. \& Silveira, D. T. (2009). Métodos de pesquisa. Editora da UFRGS.

Gil, A. C. (1994). Métodos e técnicas de pesquisa social (4a ed.). Atlas.

Gimonet, J. C. (2007). Praticar e compreender a Pedagogia da Alternância dos CEFAs (trad. Thierry Burghgrave). Petrópolis: Vozes.

Grundy, S. (1987) Curriculum: Product or Praxis. Falmer Press.

Koche, J. C. (2011). Fundamentos de metodologia científica. Vozes

Lima, E. S. O Currículo das Escolas do Campo: Perspectivas de Rupturas e Inovação. Academia.edu. https://www.academia.edu/34862618/O_CURR\% C3\%8DCULO_DAS_ESCOLAS_DO_CAMPO_PERSPECTIVAS_DE_RUPTURAS_E_INOVA\%C3\%87\%C3\%830.

Martins, J. S. \& Lima, A. R. (2001). Educação com o pé no chão do sertão: proposta Político Pedagógica para as escolas Municipais de Curaçá. Curaçá: IRPAA/PMC/UNICEF/Fundação Abrinq.

Oliveira, A. P. (2013, junho). Casa Familiar Rural e Pedagogia da Alternância: Uma metodologia viável para a educação no campo. II Encontro de Pesquisas e Práticas em Educação do Campo da Paraíba, João Pessoa, PB, Brasil.

Queiroz, J. B. P., Silva, V. C. \& Pacheco, Z. (2006). Pedagogia da alternância: construindo a educação do campo. Ed. Universa.

Sacristán, J. C. (2000). O currículo uma reflexão sobre a prática. Artmed.

Sousa, A. M. \& Garcia, R. P. M. (2020). Parâmetros de Enquadramento como Escola do Campo, um Olhar Sobre o Município de Presidente Tancredo Neves, Bahia. Brazilian Journal of Development, 6 (11), 84406-84418. https://www.brazilianjournals.com/index.php/BRJD/article/view/19257/15449.

Teixeira, E. S., Bernartt, M. L. \& Trindade, G. A. (2008). Estudos sobre Pedagogia da Alternância no Brasil: revisão de literatura e perspectivas para a pesquisa. Educação e Pesquisa, 34 (2), 227-242. https://www.redalyc.org/articulo.oa?id=29811390002.

Triviños, A. N. S. (1987). Introdução à pesquisa em ciências sociais: a pesquisa qualitativa em educação. Atlas.

União Nacional das Escolas Famílias Agrícolas do Brasil - UNEFAB (2000). Etapas do relacionamento aluno-escola-família. Anchieta: Escolas Famílias Agrícolas. (texto para discussão) 